\title{
Alternative Approach for Drought Tolerance; Seed Priming and Physiology
}

\author{
Elif Özdemir ${ }^{1}$ and Bayram Sade ${ }^{1}$ \\ ${ }^{1}$ Selcuk University; Agriculture Faculty, Crop Science Departmant, Konya/TURKEY
}

\begin{abstract}
Biotic and abiotic stress factors may cause yield loss in plants and affect human and animal nutrition. Amount of lacking yield due to biotic and abiotic stress factors ranged between 65 and 87\% [1][2][3]. So many studies were conducted finding a new method to use limited water resources effectively especially crops cultivating areas that exposed to drought. Seed priming which is one of those studies is a controlled hydration process. Seed priming triggers progressing of metabolic activities (physically and chemically) while radicle protrusion is avoided. Researchers report that priming increase seedling emergence uniformity rate, trigger growing especially under stress conditions and have different effects under different stress conditions [4]. Seed priming treatments provides increase of some free radical scavenging enzymes like SOD(superoxide dismutase), CAT(catalase) and POX(peroxidase) and trigger synthesis of proline that is an osmoprotectant also provide vigorous seedling formation [5][6][7]. Increasing of those kind of enzymes provides degradation of free radicals like singlet oxygen, hydroxyl radical and hydrogen peroxide which cause degradation of membrane lipids, proteins, enzymes, pigments and nucleic acids [8]. It's thought that evaluating of alternative approaches like seed priming in terms of physiology will provide benefits to farmers that cultivate at drought areas.
\end{abstract}

Keywords: Physiology, Drought, Proline, Antioxidant Enzymes, Priming

\section{Drought and Seed Priming}

Drought is one of the most limiting factors to the crop productivity. Drought stress is one of the main causes for crop yield reduction in the majority of agricultural regions of the world. It has different effects on plant growth stages and the plant material that will be harvested. The detrimental drought effects lose in yield and quality; and the death of plant. Drought is a condition when an area faces lack of precipitation and has high evapotranspiration resulting non-availability of water (Anonymous, 2010a).

There are different types of drought;

\subsection{Meteorological drought}

Meteorological drought is defined as the deviation of values from normal rainfall for a specific period (at least 30 years). These definitions are usually territorial and based on understanding of the regional climatology. Under normal conditions, meteorological measurements are used as an indicator of expressing drought. An ongoing meteorological drought could be stronger quickly or finished suddenly [2][9].

\subsection{Agricultural drought}

Agricultural drought is related with various characteristics of meteorological drought and is defined as the absence of water needs of plant, seen during limitation of water resources and in moisture periods. In this kind of drought, falling period is more important than amount of precipitation. It will be useful if rainfall comes in the right stage of plant development. Amount of precipitation may not be much, but if the time of precipitation is suitable for plant development, meteorological drought may occur but agricultural drought does not seem because of plant's water procurement [2][10].

\subsection{Hydrological drought}

Hydrological drought means absence of earth and underground water resources due to long-lasting reduction of precipitation. The kind of drought may be traced by measurement of lakes, reservoirs and underground water levels. Generally, hydrological measurements are not the only indicator of drought. It is possible to see hydrological drought after a long time of meteorological drought [9]. The frequency and severity of hydrological 
drought is often defined on a watershed basin scale. Although, climate is a primary contributor to hydrological drought, other factors such as changes in land use, land degradation, and the construction of dams also affect the hydrological characteristics of water resources [2][10].

\subsection{Physiological drought}

Physiological drought is defined as a state of water expressed by the water content limiting the plant production in the soil root zone. The expression physiological drought seems to be a better characteristic to specify the water deficiency for plants. Its relation to different types of drought is not unambiguous; even if the meteorological drought exists, it does not necessarily mean physiological or hydrological drought. Accordingly, the stage of physiological drought depends on the plant type, especially on the ontogenesis stage of a particular plant [11]. During physiological drought, plant cannot use water in the soil because of the unsuitable formation. Due to the low temperature or freezing of soil, water plants cannot take water by roots; when plants are faced with physiological drought, they try to keep water by removing their leaves [2][10].

There a lot of physiologic effects of drought on plants. They can be summarized as below [12].

- For cell division cells must be in turgor. At water deficit condition cell division is decrease or stop by time.

- Protein synthesis reduces during drought.

- At water deficit condition during vegetative phase leaf area and stomatal conductance decrease. According to this assimilation affected negatively.

- Chlorophyll synthesis decreases severe water deficit condition.

- At drought conditions although decrease activities of some enzymes like nitrate reductase, hydrolytic enzymes activities increase like amylase.

- At extreme water deficit level respiration, $\mathrm{CO}_{2}$ assimilation, transport and xylem activities reduce.

- By reduction of plant water potential, concentration of some hormones changes. ABA increase at leaf and organs. This hormone triggers stomatal closure and cause reduction of $\mathrm{CO}_{2}$.

- During vegetative phase those symptoms disappear by irrigation but old leaves can die at these conditions and fresh leaves become smaller. Leaves can need time to start photosynthesis again.

- Water deficit during generative phase has worst effects on plant development [12].

Drought tolerance means plant's adaptation to drought or arid conditions by modifying physio-morphic features. These features include leaf water potential, stomatal frequency, stomatal size, osmotic adjustments [13]. One of the most crucial functions of plants is responding and adapting to stress for self-defense by expression of certain genes. Drought stress induces several physiological, biochemical and molecular responses in crops, which may sometimes help them adapting to limited environmental conditions. Like drought, several different abiotic stresses result in water stress like salt and cold stresses.

Various abiotic stresses lead to the overproduction of ROS (reactive oxygen species) in plants which are highly reactive and toxic and cause damage to proteins, lipids, carbohydrates and nucleic acids. The oxidative stress tolerance is genetically controlled. Those kinds of plants are obtained by breeding and selection, transgene production or adopting physiological approaches like seed-priming.

Seed priming is a controlled hydration technique, which permits the germination metabolism without the actual germination. For priming, seeds are soaked in solutions then rinsed thoroughly after removing from the priming solutions [14]. Among various strategies priming is an easy, low cost, low risky and effective approach to overcome the environmental stresses [16][15]. It is necessary to alleviate the adverse effects of drought stress for achieving good crop yields [17].

\section{Priming: Definition and Types}

The word priming refers to seed hydration or providing seed moisture followed by its drying, so germination process begins. Priming hastens the germination, seedling emergence and early growth [13]. Researchers defined priming as a method used by farmers at a wide range of plants, including wheat and chickpea. Seeds are treated solutions for about $6 \mathrm{~h}, 12 \mathrm{~h}, 24 \mathrm{~h}$, then dried till back no treated moisture level. Priming is an easy technique for farmers who cannot use expensive and complex methods at field conditions [18]. Solutions that will be used priming, determined according to aim of study. Cytokinins have interactions with some hormones like ABA and 
Auxins and increase salt tolerance. It is reported that seed priming with kinetin cause reduction of ABA of plants and this reduce effects of salt stress.

Sometimes plants produce polyamines to eliminate unfavorable conditions' effects. Some researchers use this way to prevent harmful components also. They increased polyamine level by artificial ways like seed priming with polyamines and induce salt tolerance. This method can also be used to increase nutrients of seeds. So especially farmers whose soils have $\mathrm{Zn}$ deficiency, prime seeds with $\mathrm{ZnSO}_{4}$ before sowing. The various approaches include hydro priming, osmo priming, chemical priming, hormonal priming, biological priming, redox priming, solid matrix priming, etc. Although priming improves the rate and uniformity of seedling, emergence and growth particularly under stress conditions, the effectiveness of different priming agents varies under different stresses and with different crop species [19][4].

There are different types of treatments like;

- Hydro priming (Distilled water)

- Osmo priming

$>$ Nutrient priming $\left(\mathrm{ZnSO}_{4}\right.$, Ascorbic acid $)$

$>$ Hormonal priming $\left(A B A, G A_{3}, I A A\right.$, Salicylic acid)

$>$ Redox priming (Thiol compounds, $\mathrm{H}_{2} \mathrm{O}_{2}, \mathrm{NO}$ )

$>$ Chemical priming (Butenolide, Selenium, $\mathrm{CuSO}_{4}, \mathrm{ZnSO} 4, \mathrm{KH}_{2} \mathrm{PO}_{4}$, Ethanol, Putrescine, Pacloburazol, Chitosan) [19].

- Matri priming

\subsection{Hydro priming}

Seeds are soaked with distilled water, waited determined before. This is the easiest and oldest priming method. At this method there is no chemical, so during priming no chemical accumulation observed on seeds [18] [20].

\subsection{Osmo priming}

Seeds are soaked with a low potential osmotic solution and provided controlled water uptake. During this process radicle protrusion is prevented [18][20].

\subsection{Matri priming}

At this method a solid material like vermiculite whose matric potential is low is used as priming agent. Seeds are waited priming material between 1-14 days changed to plant [18][20].

\section{Effects of Priming}

Plants are exposed to any number of potentially adverse environmental conditions such as water deficit, high salinity, extreme temperature, submergence, etc. these abiotic stresses adversely affect the plant growth and productivity. Nowadays various strategies are employed to generate plants that can withstand these stresses. In recent years, seed priming has been developed as an indispensable method to produce tolerant plants against various stresses [19].

Drought stress effects seed germination and seedling growth of many plants. Seed priming could be used to alleviate the depressive effects of drought stress. The improving effects are influenced by many factors including priming methods, plant species and drought intensity [16]. Different types of priming treatments were recorded to enhance drought tolerance in many plants. Seed priming with ascorbic acid, potassium salts improved the drought resistance of wheat [16][21].

- Hydro priming improved seed germination and seedling emergence of lentil.

- $\mathrm{KNO}_{3}$ and hydro priming increased sunflower germination and seedling growth under salt and drought stresses [22].

- Seed priming with PEG increased the germination and early seedling growth of barley under drought stress condition [16]. 
- Seed priming with PEG and water increased drought stress tolerance in seeds of rice cultivars at the germination stage [16][23].

Priming could be done with a number of chemicals including silicon, which is an effective barrier against water losses by cuticular transpiration and/or fungal infections. Silicon enables the plant to tolerate drought and increase uptake of water, which in return will help the plant to produce drier mass and higher yield. Similarly priming with gibberellic acid $\left(\mathrm{GA}_{3}\right)$ enhanced the germination rate, reduced detrimental effects of salt stress, leaf water contents, increases leaf area and chlorophyll contents [13] [24].

Several investigations confirmed that seed priming has many benefits like;

- Early and rapid emergence,

- Stand establishment,

- Higher water use efficiency,

- Deeper roots, increasing root growth,

- Uniformity in emergence,

- Germination in wide range of temperature,

- Break of seed dormancy,

- Initiation of reproductive organs,

- Better competition with weed,

- Early flowering and maturity,

- Resistance to environmental stresses (such as drought and salinity) and diseases (Sclerotium rolfsii 1.),

- Higher grain yield in wheat (Triticum aestivum 1.), corn (Zea mays 1.), canola (Brassica napus 1.), pearl millet (Pennisetum glaucum 1.), chickpea (Cicer arietinum 1.), rice (Oryza sativa 1.) Lettuce (Lactuca sativa 1.) [25].

Climate change triggers and exacerbates more extreme weather events, such as drought episodes and cold snaps, which threaten crop growth and productivity. Low temperature stress in spring occurring at jointing stage could severely limit plant growth and cause considerable yield loss in wheat.

Cold acclimation in plant is a complex process involving many morphological, physiological and biochemical changes, including a significant reduction in tissue hydration during cold hardening [26].

[26] reported that in wheat, priming provides resistance to high temperature, low temperature and waterlogging at early vegetative stages and could improve the tolerance to the same stress or cross-tolerance to drought stress occurring at later growth stages.

\subsection{Physiological effects}

Seed priming induce a particular physiological state in plants by the treatment of natural and synthetic compounds to the seeds before germination. In plant defense, priming is defined as a physiological process by which a plant prepares to respond to imminent abiotic stress more quickly or aggressively. Moreover, plants raised from primed seeds showed sturdy and quick cellular defense response against abiotic stresses. Priming for enhanced resistance to abiotic stress obviously is operating via various pathways involved in different metabolic processes. The seedlings emerging from primed seeds showed early and uniform germination. Moreover, the overall growth of plants is enhanced due to the seed-priming treatments.

In most plants, drought or salinity causes a variety of biochemical, physiological and metabolic changes [27], which may result in oxidative stress and affect plant metabolism, performance and thereby the yield. Salt and osmotic stresses are also responsible for both inhibition or delayed seed germination and seedling establishment [28][19]. It was reported that osmo and hydro priming of chickpea seeds with mannitol and water alleviated the adverse effects of water deficiency and salt stress on seedling growth. The treatment of seeds with water, 2 and $4 \%$ mannitol increased the length and biomass of roots and shoots of chickpea seedlings as compared to non-primed controls under salt stressed conditions [29][30]. Osmo and hydro priming with water and mannitol were found to be effective methods to enhance the ability of salt tolerance and to improve seed 
germination and seedling growth of alfalfa under high salt stress condition. The above priming treatments significantly enhanced the activities of catalase (CAT), peroxidase (POD), superoxide dismutase (SOD) and proline content and reduced the malondialdehyde (MDA) accumulation and electrolyte leakage under the salt stress condition.

It is suggested that these priming methods could be applied in a wide range of plants at high saline soil conditions in the future [19][31].

\section{References}

[1] E. Ozdemir, B. Sade, S. Soylu, "Effects of seed priming on growth parameters and relative water content of bread wheat cultivars at drought and normal conditions" Journal of Selcuk University Agriculture and Food Sciences , vol.26, pp.25-30, 2012.

[2] B. Sade, S. Soylu, E. Yetim, "Drought and oxidative stress", African Journal of Biotechnology, vol.10, pp.1110211109, 2011.

[3] B. Kacar, V. Katkat, Ş. Öztürk, Plant Physiology, Nobel Publishes, Ankara, Turkey, 2009.

[4] M. Iqbal, M. Ashraf, "Changes in growth, photosyntetic capasity and ionic relations in spring wheat (Triticum aestivum L.) due top re-sowing seed treatment with polyamines", Plant Growth Regulation, vol. 46, pp.19-30, 2005. http://dx.doi.org/10.1007/s10725-005-5901-8

[5] I. Afzal, M. A. B. Shahzad, H. Amjad, F. Muhammed, "Physiological enhancements for alleviation of salt stres in wheat", Pakistan Journal Botanic, vol. 38, pp.1649-1659, 2006.

[6] K. Y. Chiu, C. S. Wang, J. N. Sung, "Lipid peroxidation scavenging enzymes associated with accelerated aging and hydration of water melon seeds differing in ploidy", Physiology Plant, vol.94, pp.441-446, 1995.

http://dx.doi.org/10.1111/j.1399-3054.1995.tb00951.x

[7] S. M. Chang, J. M. Sung, "Deteriorative changes in primed sweet corn seeds during storage", Seed Science Technology, vol.26, pp.613-626, 1998.

[8] R. Maheshwari, R. S. Dubey, "Nickel-induced oxidative stres and the role of antioxidant defence in rice seedling", Plant Growth Regul, vol.59, pp.37-49, 2009. http://dx.doi.org/10.1007/s10725-009-9386-8

[9] Anonymous (2010a); Government meteorology management; http://www.meteor.gov.tr (Accessed 11.11.2010).

[10] Anonymous (2010b); Pasific diseaster centre; http://www.pdc.org (Accessed 11.11.2010).

[11] V. Novak, "Using the sensitivity of biomass production to soil water for physiological drought evaluation", Soil Water Res., vol.3, pp.116-122, 2009.

[12] B. Sade, Plant physiology; Agriculture Faculty Publishing, Konya, Turkey, 113 pgs.

[13] M. Ahmet, A. Kamran, M. Asif, Q. Ummara, Z. I. Ahmed, G. Aakash, "Silicon priming: a potential source to impart abiotic stress tolerance in wheat: A review", Australian Journal of Crop Science, vol.4, pp.484-491, 2013.

[14] S. Hussain, M. Farooq, A. M. Wahid, "Seed priming with putrescine improves the drought resistance of maize hybrids" International Journal of Agriculture and Biology, vol.15, pp.1349-1353, 2013.

[15] A. Goswami, R. Banerjee, R. Raha, Sanghamitra, "Drought resistance in rice seedlings conferred by seed priming", Protoplasma, vol. 250, pp.1115-1129,2013. http://dx.doi.org/10.1007/s00709-013-0487-x

[16] M. Yan, "Seed priming stimulate germination and early growth of Chinese cabbage under drought stress", South African Journal of Botany, vol. 99, pp. 88-92, 2015.

http://dx.doi.org/10.1016/j.sajb.2015.03.195

[17] M. Ashraf, H. Rauf, "Inducing salt tolerance in maize (Zea mays L.) through seed priming with chloride salts, growth and ion transport at early growth stages", Acta Physiologiae Plantarum, vol.23, pp.407-414, 2001.

http://dx.doi.org/10.1007/s11738-001-0050-9

[18] E. Ozdemir, "Effects of seed priming on physiological parameters of bread wheat (Triticum aestivum L.)", M.S. Thesis, Dep. Naturel and Applied Sciences, Selcuk Univesity, Konya, Turkey, 2012.

[19] K. C. Jisha, K. Vjayakumari, J. T. Puthur, "Seed priming for abiotic stress tolerance: an overview", Acta Physiol Plant, vol.35, pp.1381-1396, 2013.

http://dx.doi.org/10.1007/s11738-012-1186-5 
[20] E. Elkoca, "Priming; treatments before sowing", Journal of Atatürk University Agriculture Faculty, vol.38, pp.113$120,2007$.

[21] M. Farooq, I. Irfan, T. Aziz, I. Ahmad, S. A. Cheema,"Seed priming with ascorbicacid improves drought resistance of wheat" Journal of Agronomy and Crop Scienc, vol.199, pp.12-22, 2013.

http://dx.doi.org/10.1111/j.1439-037X.2012.00521.x

[22] M. D. Kaya, G. Okcu, M. Atak, Y. Cıkıhı, O. Kolsarıcı, "Seed treatments to overcomesalt and drought stress during germination in sunflower (Helianthus annuus L.)”, European Journal of Agronomy, vol. 24 (4), pp.291-295, 2006. http://dx.doi.org/10.1016/j.eja.2005.08.001

[23] Y. Y. Sun, Y. J. Sun, M. T. Wang, X. Y. Li, X. Guo, R. Hu, M. A. Jun, "Effects of seed priming on germination and seedling growth under water stress in rice", Acta Agronomica Sinica, vol.36 (11), pp.1931-1940, 2010. http://dx.doi.org/10.1016/S1875-2780(09)60085-7

[24] H. M. Ali, M. H. Siddiqui, M. O. Basalah, M. H. Al-Whaibi, A. M. Sakran, A. "Effects of gibberellic acid on growth and photosynthetic pigments of Hibiscus sabdariffa L. under salt stress", Afric J Biotech, vol.11 (4), pp.800-804, 2012.

[25] A. Eivazi, "Induction of drought tolerance with seed priming in wheat cultivars (Triticum aestivum L.)", Acta Agriculture Slovenica, vol. 99(1), pp.21-29, 2012. http://dx.doi.org/10.2478/v10014-012-0003-6

[26] L. Xiangnan, H. B. Topbjerg, D. Jiang, F. Liu, "Drought priming at vegetative stage improves the antioxidant capacity and photosynthesis performance of wheat exposed to a short-term low temperature stress at jointing stage", Plant Soil; DOI 10.1007/s11104-015-2499-0, 2015 http://dx.doi.org/10.1007/s11104-015-2499-0

[27] L. Xiong, J. K. Zhu, "Molecular and genetic aspects of plant responses to osmotic stress", Plant Cell Environ., vol.25, pp.131-139, 2002. http://dx.doi.org/10.1046/j.1365-3040.2002.00782.x

[28] M. Almansouri, J. M. Kinet, S. Lutts, "Effect of salt and osmotic stresses on germination in durum wheat (Triticum durum Desf.)", Plant Soil, vol. 231, pp.243-254. 2001. http://dx.doi.org/10.1023/A:1010378409663

[29] S. Kaur, A. K. Gupta, N. Kaur, "Effect of osmo and hydropriming of chickpea on seedling growth and carbohydrate metabolism under water deficit stress", Plant Growth Regul., vol. 37, pp.17-22, 2002. http://dx.doi.org/10.1023/A:1020310008830

[30] S. Kaur, A. K. Gupta, N. Kaur, "Seed priming increases crop yield possibly by modulating enzymes of sucrose metabolism in chickpea", J. Agron. Crop. Sci., vol.19, pp.81-87, 2005.

http://dx.doi.org/10.1111/j.1439-037X.2004.00140.x

[31] R. Amooaghaie, "The effect of hydro and osmopriming on alfalfa seed germination and antioxidant defenses under salt stress", Afr. J. Biotechnol, vol.10, pp.6269-6275, 2011. 